\title{
QUASICLASSICAL MODELS OF ELECTRON TRANSPORT PHENOMENA IN THIN METAL FILMS
}

\author{
Z. V. Stasyuk \\ Department of Physics, Lviv State University, \\ 50 Drahomanov Str., Lviv, UA-290005, Ukraine \\ (Отримано 29 травня 1998 р.; в остаточному вигляді - 16 лютого 1999 р.)
}

\begin{abstract}
The main theoretical models of the classical size effect in thin metal films are analysed. A new model of charge transport in a thin polycrystalline film is suggested. It is assumed that a polycrystalline film consists of the grains which are situated in the layer with a heterogeneous cross-section. The amplitude of surface macroscopic roughness is commensurable with the average grains radius. The development of this model allowed us not only to describe the surface and grainboundary scattering of charge carriers in polycrystalline films, but also to estimate the middle value of surface roughness parameter. The derived theoretical expressions were used to explain the experimental data.
\end{abstract}

Key words: thin film, surface and grain-boundary scattering, size effect.

PACS number(s): 73.50.-h

\section{INTRODUCTION}

Thin films are the subject of great attention in many theoretical and experimental investigations. The interest in film properties is caused on the one hand by the extensive perspectives of practical application of thin films in new technologies. On the other hand the investigation of thin films allows to obtain a very interesting information about some fundamental properties of solids and their surfaces. The study of electrical properties of thin films was begun by J. J. Thomson, who was the first to explain thin film resistivity deviation from those of bulk metal as a result of additional scattering of electrons by surfaces. There were many attempts to describe the electrical properties of the finite size samples. In most cases the sample size limit does not lead to deflections of thin metal films electronic structure, and the surface influence results as an additional source of electron scattering. On the other hand the thin films structure is usually more imperfect than the bulk material structure. A fine-grained polycrystalline thin film consists of a great number of crystallites. The grain boundaries in this case are also scattering centers. In this paper we shall analyse the main theoretical models of charge transport in thin films. We shall propose some supplements to these models.

\section{PARALLEL-PLANE FILM MODEL}

The first consistent theory of the electron transport in thin metal films was suggested by K. Fuchs [1] who proposed the model of uniform and homogeneous parallelplane layer. The theory was developed for free electron Sommerfeld metal films. There are two sources of electron scattering in thin film: the background (volume) scattering, available in bulk materials, and surface scattering the relative contribution of which depends on the thin film thickness $d$. An expression for thin film conductivity is derived by considering the statistical distribution of all the electrons and solving the Boltzmann transport equation with the appropriate boundary conditions. Fuchs at first assumed that electrons were diffusely scattered at the surfaces and lost their momentum in the direction of the applied electrical field (i.e. all electrons were unspecularly reflected) and then modified this theory by assuming that the fraction $p$ of electrons was reflected specularly from the surfaces and the fraction $(1-p)$ of electrons was scattered from the surfaces nonspecularly. Sondheimer [2] extended this theory to galvanomagnetic effects. The famous Fuchs-Sondheimer (F-S) expression for thin film conductivity is as follows:

$$
\begin{aligned}
\sigma_{\infty} / \sigma & =\rho / \rho_{\infty}=\left[1 / k-3 / 8 k^{2}\right. \\
& \left.+\left(3 / 8 k^{2}\right) \int_{1}^{\infty}\left(1 / a^{3}-1 / a^{5}\right) e^{-k a} d a\right] / k
\end{aligned}
$$

where $\sigma$ and $\rho$ are the conductivity and resistivity of thin films, $\sigma_{\infty}$ and $\rho_{\infty}$ are the same parameters characterizing the infinitely thick film; $k=d / \lambda, d$ - is the film thickness and $\lambda$ - is the mean free path of electrons in the infinitely thick film. The approximate expressions are often used in practice. For thick films $(d>>\lambda)$ the following expression is used:

$$
\rho / \rho_{\infty}=1+3(1-p) / 8 k
$$

In the same manner the equations characterizing the size dependence of the temperature coefficient of resistance (TCR) $\beta$, the Hall coefficient $R^{2}$ and thermoelectric power $S^{3}$ were obtained. The $\mathrm{F}-\mathrm{S}$ theory is widely used to analyse experimental results in metal films. The theory was improved by many investigators, in particular by Lucas, Ziman, Soffer, Parrot and Cottey. Yet it 
has the following basic deficiencies:

- F-S theory doesn't pay attention to real electron structure features of thin film's material. The theory is developed for an ideal Sommerfeld metal.

- The theory neglects the contribution of various statical defects of thin film structure on the electron scattering process. The influence of grainboundary scattering on the electron transport is not examined.

- In the equations for kinetic coefficients there are three transport parameters $p, \lambda$ and $\rho_{\infty}$ (or $\beta_{\infty}$, $\left.R_{\infty}, S_{\infty}\right)$, which are assumed to remain constant. This is actually not true. The mentioned parameters may be considered as characteristics of a given thin film and they cannot be expressed unequivocally with the help of the bulk material's parameters.

- The theory assumes a film to be a plane parallel layer. The real film is not a plane parallel slab. There are macroscopic thickness nonuniformities in a real film. Some of the mentioned deficiencies of the $\mathrm{F}-\mathrm{S}$ theory were improved in further investigations.

\section{NAMBA MODEL}

Namba [4] proposed to include the influence of the geometrical nonuniform cross-section of the film due to macroscopic surface roughness into the expression for the thin film resistivity. The surface roughness profile was represented as one-dimensional function in the current flow direction. It was supposed that the local film thickness deviation from the average thickness could be expressed by sine-shaped function. The local film thickness $d(x)$ at the point $x$ can be expressed by:

$$
d(x)=\bar{d}+h \cdot \sin 2 \pi x / L
$$

where $\bar{d}$ is the average film thickness, $h$ is the amplitude of the film roughness and $L$ is the roughness correlation length. Thus, the overall film resistivity $\rho$ is expressed as

$$
\rho=(\bar{d} / L) \cdot \int_{0}^{L} \rho[d(x)] / d(x) d x
$$

where $\rho[d(x)]$ is the local film resistivity calculated according to $\mathrm{F}-\mathrm{S}$ theory. The experimental results can be fitted by equation (4), using $h$ as the fitting parameter. The Namba model leads to a stronger increasing of film resistivity with decreasing of film thickness than the plane-parallel model predicts. The Namba model is useful for very thin films. The application of equation (4) to analyze the experimental results allows to estimate the film's roughness average amplitude. The main weaknesses of this model are: (1) the model is essentially onedimensional, (2) the sine function is not a good approximation of real thin film thickness deviations. It must be noticed that the attempt to take into account the existence of two-dimensional surface roughness immediately makes the calculation unpreciselly inaccurate, because the additional fitting parameter is necessary. The Namba model does not pay any attention to the structure of thin films, including the grain-boundaries existence.

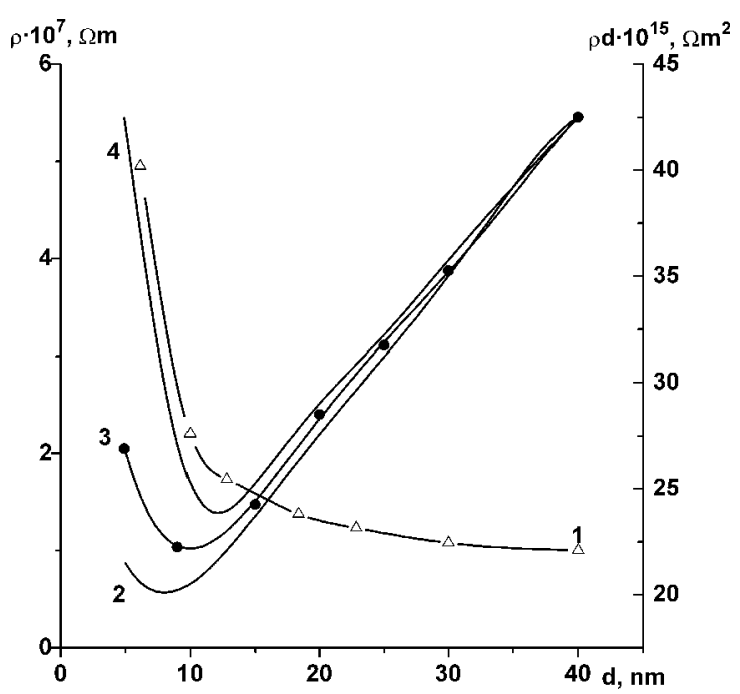

Fig. 1. Thickness-dependent resistivity of nickel films prepared in vacuum $10^{-7} \mathrm{~Pa}(1)$. The theoretical curves computed for $\rho \cdot \bar{d}=f(\bar{d})$ with the help of expression (9). Parameter $h=2,4 \mathrm{~nm} \mathrm{(2),} h=3,1 \mathrm{~nm}(3), h=3,8 \mathrm{~nm}$ (4). The experimental data are shown as points.

\section{THE INTERNAL SIZE-EFFECT}

The contribution of crystalline boundaries to total electron scattering in the film is important because the typical grain size is often comparable to the electron mean free path $\lambda$. It is expected that scattering at grain boundaries will make a significant contribution to the film resistivity. This effect will be particularly strong in fine-grained films. In some cases when the linear grain sizes depend on the film thickness, the F-S model can not be used for the description of the film's resistivity size dependence. The corresponding $\rho_{\infty}$ value is necessary for every crystalline linear size, because the film structure changes with the film's thickness variation. In general, such a conclusion can be made from internal sizeeffect models analysed below. The first grain-boundary electron scattering model was developed by Mayadas and Shatzkes [5] (M-S model). The grains are assumed to have equal size and separated by grain boundaries, which are perpendicular to the film planes. The grainboundary scattering occurs in the film simultaneously 
with the isotropic background scattering. The grainboundary scattering effect on the electron transport in the film is described in terms of the structural parameter $\alpha$ which describes the geometry of grain and scattering power of its boundaries:

$$
\alpha=\lambda_{0} \cdot r / D(1-r)
$$

where $D$ is the average grain diameter, $r$ is the grain boundary reflection parameter with the values between 0 and $1, \lambda_{0}$ is the mean free path of electrons in bulk crystal. The ratio of the bulk resistivity $\rho_{0}$ to the resistivity of infinitely thick polycrystalline film $\rho_{\infty}$ can be simplified in such a way:

$$
\begin{aligned}
\rho_{0} / \rho_{\infty} & =f(\alpha)=3 \cdot[1 / 3-\alpha / 2 \\
& \left.+\alpha^{2}-\alpha^{3} \ln (1+1 / \alpha)\right]
\end{aligned}
$$

A further extension of the $\mathrm{M}-\mathrm{S}$ model was given by Tellier, Tosser, Pichard, Warkusz, et all. Due to their efforts, the one-dimensional $\mathrm{M}-\mathrm{S}$ model was transformed to a model which is useful to describe the transverse effects, such as the Hall effect. The electron transport phenomena in single crystalline, polycrystalline films and films grown in a columnar fashion were described. The expressions obtained in the investigations were widely employed to explain the experimental data. The grainboundary effect on the electron transport is characterized by the parameter $t$. This parameter expresses the probability of electron transmission through a grain boundary. Tellier, Tosser and Pichard had studied the properties of the parameter $t$. The parameter $t$ does not depend on the temperature [6] and energy of electrons [7]. The grainboundary scattering in polycrystalline films is isotropic. Grain configuration deviation from a cubic shape does not have an influence on the grain-boundary scattering [8]. The correlation between infinitely thick film resistivity $\rho_{\infty}$ and the analogous bulk crystal parameter $\rho_{0}$ for a polycrystalline film approximately may be expressed as:

$$
\rho / \rho_{0} \approx 1+3 \lambda_{0}(1-t) / D(1+t)
$$

The resistivity temperature coefficient of an infinitely thick film $\beta_{\infty}$ may be evaluated using the correlation $\beta_{\infty} / \beta_{0} \sim \rho_{0} / \rho_{\infty}$ and the Hall coefficient $R_{\infty} \approx R_{0}$. The main deficiency of the internal size effect theory is as follows. The influence surface scattering on the charge transport in the film is taken into account in the same way as in the $\mathrm{F}-\mathrm{S}$ theory. The film surfaces are considered to be parallel planes. There are only point scattering centres on these planes. A real polycrystalline film is not a parallel plane. Therefore the macroscopic thickness nonuniformities can influence the transport of charge carriers in a thin film.

\section{THE HETEROGENEOUS CROSS SECTION POLYCRYSTALLINE FILM MODEL}

For the first time such a model was proposed in our paper [9]. From the point of view suggested in [9] the most realistic model of the geometrical structure of a polycrystalline metal film is the following one. The polycrystalline film consists of the crystallites situated randomly in a layer of heterogeneous cross-section. The amplitude of surface macroscopic roughness is commensurable with the average grain radius. Of course, the main mechanisms of electron scattering in a polycrystalline film besides the volume scattering are surface and grainboundary scattering. The most realistic theory of grainboundary scattering in a polycrystalline film have been developed by Tellier, Tosser and Pichard (T-T-P theory). The surface scattering in this theory has been described by the Cottey-model [10] which is the development of plane-parallel model. Namba's model of the heterogeneous cross-section layer may be used to describe the influence of surface scattering on the electron transport in a polycrystalline film, because the real film's surface is not a plane. Therefore, the expressions derived in the framework of the $\mathrm{M}-\mathrm{S}$ or $\mathrm{T}-\mathrm{T}-\mathrm{P}$ theories may be substituted into expression (4) as the local resistivity to compute the resistivity $\rho$, corresponding to the average film thickness $d$. The $\rho$ value may be compared with experimental data. Similarly the average values of the other kinetic coefficients were calculated [11]. In the three-dimensional T-T-P model [12], the general formulation for the average polycrystalline film's resistivity can be written as:

$$
\left.\rho(\bar{d}) / \rho_{0}=(\bar{d} / L) \cdot \int_{0}^{L}\left\{2 \cdot[1 / \mu+(1-c) / \nu] /(\bar{d}+h \cdot \sin (2 \pi x / L)) \cdot\left[a-0.5+\left(1-a^{2}\right) \cdot \ln (1+1 / a)\right]\right)\right\} d x
$$

with

$$
\begin{gathered}
a=\left(1+c^{2} / \nu\right) /[1 / \mu+(1-c) / \nu] ; \quad c=4 / p \\
\mu=d(1+p) / 2 \lambda_{0}(1-p) ; \quad \nu=D(1+t) / 2 \lambda_{0}(1-t)
\end{gathered}
$$

In the framework of this model some approximate expressions which are useful to the analysis of experimental data were obtained. The modified M-S expression for the film's resistivity may be written in such a form: 


$$
\rho(\bar{d}) / \rho_{0}=\left\{1+3 \lambda_{0} f(\alpha)\right\} / 8 \bar{d}\left[1-(h / \bar{d})^{2}\right] / f(\alpha)\left[1-(h / \bar{d})^{2}\right]^{\frac{1}{2}}
$$

Expressions (8) and (9) were used in our previous experimental investigations to fit the theoretical dependences to the experimental data for $\mathrm{V}$ and $\mathrm{Pd}$ films [13]. As an example in Fig. 1 the experimental data (the points) and the theoretical dependences (continuous lines) for fine-grained thin nickel films are shown. The experimental details were described in our previous investigations $[13,14]$. The $\mathrm{F}-\mathrm{S}$ model may be used to examine the experimental $\rho$ size dependence, because the average crystalline size has been found to be independent on the film thickness $(D \approx 8-10 \mathrm{~nm}$ ). In this case the $\rho \cdot d$ dependence on the film thickness $d$ must be a straight line. When the film thickness $d$ exceeds $15 \mathrm{~nm}$, the linear dependence remains, but in the $8-15 \mathrm{~nm}$ range a deviation from a straight line is observed. This deviation is caused by the film thickness irregularities. Curves 2-4 were calculated using expression (9) for the values of $h$ equalling 2.4:3.1 and $3.8 \mathrm{~nm}$. It is clear that the best fitting of the theoretical curve to experimental data is observed for $h=3.1 \mathrm{~nm}$. This result agrees well with the STM data obtained by Hoffmann, Vancea and Jacob [15] for the nickel film surface roughness.

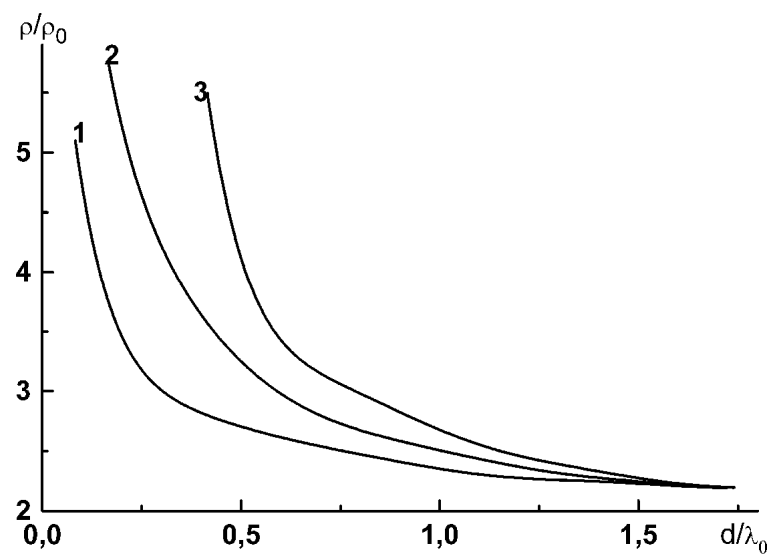

Fig. 2. The theoretical curves for $\rho / \rho_{0}$ size dependences: $h=0(1), h=D[1-\exp (-2 d / D)] / 2(2), h=D / 2$.

The analysis of the results of experimental investigations shows that the value $h$ is usually slightly smaller than the average grains radius: $h \leq D / 2$. In some cases the surface roughness amplitude is not constant and depends on the film average thickness because the average grain size depends on the film thickness, too. So, the $h$ value is a film thickness function $h=h(d)$. The substitution of $h=h(d)$ into expression (8) is needed to calculate the resistivity thickness dependence. This problem cannot be solved in some cases, but sometimes the problem may be simplified. In very thin films the average crystallite linear size usually diminishes when film thickness decreases. In this case a $h(d)$ function may be introduced: $h(d)=h_{0}\left[1-\exp \left(-d / h_{0}\right)\right]$, where $h_{0}$ is the surface roughness amplitude in an infinitely thick film $(d \rightarrow \infty)$. The fitting precision may be increased when the next substitution is introduced $h_{0}=D / 2$, where $D$ is the average grain diameter in a sufficiently thick film. The parameter $D$ may be found as a result of electron microscope or electron diffraction investigations. In this case the fitting parameter $h$ is not needed and the general expression analogous to (8) is as follows:

$$
\begin{aligned}
\rho(\bar{d}) & =(\bar{d} / L) \cdot \int_{0}^{L}\{2 \rho[d(x)\} \\
& \times\{2 \bar{d}+D[1-\exp (-2 \bar{d} / D)] \sin (2 \pi x / L)\}^{-1} d x
\end{aligned}
$$

The function $h(d)$ which depends on thickness weakens a sharp rising of resistivity when thickness $d$ approaches $h_{0}$. Fig. 2 is given to illustrate the differences between the $\mathrm{T}-\mathrm{T}-\mathrm{P}$ model and the models proposed in this paper. One can see that for the T-T-P model $\rho$ asymptotically approach $\infty$ as $d \rightarrow 0$. The thickness dependence of $\rho$ calculated by expression (8) rises to $\rho \rightarrow \infty$, when $d \rightarrow h_{0}$. The calculations carried out with the help of expression (10) gave us an intermediate result.

\section{CONCLUSIONS}

The basic models for the electron transport in thin metal films were analysed. The combined quasiclassical model of the charge transport in very thin continuous polycrystalline films has been developed. In the framework of the proposed model the approximate equations which are useful to experimental data explanation have been suggested. Quantum transport theories in metallic films developed in recent years (for example, [16-19]) give the same results for the electron transport in continuous metallic films, as the theory presented above. The advantage of the quasiclassical model is a possibility to account in addition for the grain boundary scattering contribution to the total relaxation time. 
[1] K. Fuchs, Proc. Cambrige Philos. Soc. 34, 100 (1938).

[2] E. H. Sondheimer, Adv. Phys. 1, 1 (1952).

[3] E. Justi, M. Kohler, G. Lautz, Z. Naturforsch. 6a, 456 (1951).

[4] Y. Namba, Jap, J. Appl. Phys. 9, 1326 (1970).

[5] A. F. Mayadas, M. Shatzkes, Phys. Rev. B 1, 1382 (1970).

[6] C. R. Pichard, A. J. Tosser, C. R. Tellier, Electrocomp. Sci. Technol. 7, 217 (1981).

[7] C. R. Tellier, A. J. Tosser, L. Hafid, J. Mater. Sci. 15, 2875 (1980).

[8] C. R. Pichard, C. R. Tellier, L. Quarbya, A. J. Tosser, Le Vide, Les Couches Minces 210, 3 (1982).

[9] Z. V. Stasyuk, Ukr. Fiz. Zhurn. 31, 742 (1986).

[10] A. A. Cottey, Thin Solid Films 1, 297 (1968).

[11] Z. V. Stasyuk, in Fiziko-khimichieskiie, strukturnyie, i emisionnyie svoistva tonkikh plionok i povierkhnosti tviordykh tiel (Physical-chemical, structural and emission properties of thin films and solid surfaces), edited by N. Nakhodkin (UMK VO, Kyiv, 1992), p. 212.

[12] M. Bedda, C. R. Pichard, A. J. Tosser, J. Mater. Sci. 21, 1405 (1986).

[13] I. M. Duma, K. G. Lakh, B. L. Melnichuk, Z. V. Stasyuk, Металлофиз. нов. технол. 15, 60 (1993).

[14] B. L. Melnichuk, Z. V. Stasyuk, Физ. мет. металлов. 73, 236 (1992).

[15] H. Hoffmann, J. Vancea, U. Jacob, Thin Solid Films 129, $181(1985)$

[16] Z. Tesanovic, M. Jaric and S. Maekawa, Phys. Rev. Lett. 57, 2760 (1986).

[17] G. L. Sheng, D. Y. Xing, Z. D. Wang, Phys. Rev. B 51, 7325 (1995).

[18] X.-G. Zhang, W. H. Butler, Phys. Rev. B. 51, 10085 (1995).

[19] N. M. Makarov, A. Z. Moroz, V. A. Yampol'skii, Phys. Rev. B 52, 7325 (1995).

\title{
КВАЗІКЛ АСИЧНІ МОДЕЛ Я ЯВИШ ПЕРЕНОСУ ЗАРЯДУ В ТОНКИХ МЕТАЛЕВИХ ПЛІВКАХ
}

\author{
3. В. Стасюк \\ Фізичний факультет Львівського державного університету імені Івана Франка \\ вул. Драгоманова, 50, 290005, Львів, Украӥна.
}

Проаналізовано основні теоретичні моделі класичного розмірного ефекту в тонких металевих плівках. Запропоновано нову модель опису явищ переносу в тонких полікристалічних плівках. Зроблено припущення, що полікристалічна плівка складається з кристалітів, які формують шар неоднорідного поперечного перерізу. Амплітуда поверхневих макроскопічних неоднорідностей сумірна із середнім радіусом кристалітів. У рамках цієі моделі виявилось можливим не лише описати поверхневе та зерномежове розсіяння носіїв заряду в полікристалічній плівці, але й також здійснити оцінку середнього значення параметра поверхневих неоднорі дностей. Одер жані вирази використано для пояснення експериментальних даних. 